\title{
VARIANTES DE LA RIMA. LA RIMA AMPLIADA. LA RIMA COMPLEJA. LA RIMA EN SÍNTESIS. LA RIMA ENCABALGADA
}

\begin{abstract}
Arcadio Pardo
Resumen: La guerra civil española provocó un florecimiento de romanceros. En Francia, el poeta Louis Aragon proclama (La rime en 1940), la rima como elemento de afirmación y de resistencia contra el enemigo. Aragon experimenta nuevas modalidades de rima: las que él denomina rima "compleja", rima "en síntesis" y rima "encabalgada". Estas modalidades se encuentran aplicadas en su libro Le crève-coeur. El presente trabajo investiga igualmente la importancia de la rima "ampliada". Ejemplos de estos tipos de rima en Aragon y en poesía española. Salvo la rima ampliada, estas modalidades no han tenido continuadores.
\end{abstract}

Palabras clave: Louis Aragon, rima compleja, rima en síntesis, rima encabalgada.

Abstract: The Spanish Civil War originated an increase of romanceros. In France, the poet Louis Aragon declared (La rime en 1940) the rhyme an element of affirmation and resistance against the enemy. Aragon experiments new rhyme modalities, calling them "complex" rhyme, "synthesizing" rhyme and "overlapping" rhyme. Those modalities are applied in his book Le crève-coeur. This work also investigates the importance of the "amplified" rhyme. Examples of those sorts of rhymes can be 
found in Aragon and in Spanish poetry. Except for the amplified rhyme, those modalities did not have any followers.

Key words: Louis Aragon, complex rhyme, synthesizing rhyme, overlapping rhyme. 
«On n'en a jamais fini avec la rime. On la croit morte [...] et voilà derechef qui occupe les poéticiens, intrigue les poètes, reparaît là où on ne l'attendait plus»».

Daniel Menagre: "La rime en France de la Pléiade à Malherbe". Etudes littéraires, vol. 20, 1987, pp. 27-42.

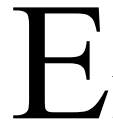

STE trabajo se propone comentar las ideas que Louis Aragon expuso sobre la rima en su escrito titulado $L a$ rime en $1940^{1}$. Esas ideas pueden ser ya conocidas entre los metricistas o aficionados a la métrica, pero seguramente no es inútil exponerlas aquí, qué antecedentes se pueden encontrar en la poesía francesa, observar si la poesía posterior las ha aplicado y también tratar de indagar en poesía española si ha habido experiencias semejantes ${ }^{2}$.

Parece cierto que la épocas de conflictos nacionales o internacionales, provocan, probablemente como apoyo moral en los protagonistas, una fuerte tendencia a rescatar de la tradición aquellas formas que pueden tener un significado de arraigo y por lo tanto, de legitimidad. La floración de romanceros durante nuestra guerra civil responde seguramente a esa "exigencia", por considerarse que el romance ha sido "la creación métrica española más genuina, más sencilla y más difundida"3 y representativa del espíritu nacional. Como los

En Euves poétiques complètes. París: Gallimard, Pléiade, I, pp. 727-733.

2 La rima en Aragon ha sido estudiada por TORLAY, Geneviève: Étude de la rime dans la poésie d'Aragon. Microforme, Lille 3: ANRT, 1987; 6 microfiches; 105 x $148 \mathrm{~mm}$. Este estudio es de consulta difícil por haber sido publicado en fichas microfilmadas que sólo se pueden leer con aparatos que no están disponibles en todas las bibliotecas.

3 PARAÍSO, Isabel: La métrica española en su contexto románico. Madrid: Arco /Libros, 2000, p 160. 
dos contrincantes -nacionalistas y republicanos- pretendían ser portadores y defensores de ese arraigo, no es de extrañar que los romanceros se multiplicasen en ambos campos ${ }^{4}$.

El período de guerra mundial, de 1939 a 1945 provoca igualmente esa necesidad de ir en busca de un apoyo nacional para difundir y exaltar los valores del pueblo y de la nación. En la Francia, ocupada por las tropas alemanas, se manifiesta también esa tendencia en el empleo de formas tradicionales en poesía como sustento y afirmación de la patria maltratada.

El título del escrito de Louis Aragon, La rime en 1940, no incluye en vano la fecha de 1940 y la mención a la rima. La fecha porque remite a una época de sometimiento nacional, y "rima" porque de todos los aspectos externos de la poesía, es ése el que se reconoce y se recuerda y es, por ser creación "nacional" en sustitución de los ritmos latinos, como un resurgimiento de los valores del pueblo.

Aragon ha podido impregnarse de la actitud de los poetas y escritores españoles de la guerra civil. Participó en movimientos intelectuales y populares en favor de la República. En la sesión de clausura del II Congreso Internacional de Escritores para la Defensa de la Cultura ${ }^{5}$, pronunció su Discours de 16 de julio 1937, publicado por la revista Commune , en el $^{6}$ que rompe con el individualismo (que él llama "analfabetismo social") para volver la mirada "aux sources vives de votre nation" y reclamar que la obra no sea como una chispa de talento individual, sino "l'expression du genre humain, parce qu'elle sera empreinte de la réalité nationale".

Pocos años antes, Aragon ya había establecido contactos con Rafael Alberti en Moscú, en casa de Lili Brik (hermana de Elsa Triolet y compañera de Maiakovski) donde Aragon leyó algunos poemas de Les communistes ont raison, conjunto

$\overline{4}$ Pueden consultarse sobre este tema los trabajos de FERNÁNDEZ PALMERAL, Ramón: "Los romanceros de la guerra civil". Revista digital Mundo Cultural Hispánico, 2005, 15 de octubre, y de SANTOJA, Gonzalo: Romancero de la guerra civil, 1984.

5 Valencia, Madrid, Barcelona, Paris, julio de 1937.

6 Commune. Agosto de 1937, $\mathrm{n}^{\circ}$ 48. Esta revista se publicó de julio de 1933 a agosto de 1939 por la l'AEAR (Association des Écrivains et Artistes Révolutionnaires). 
nunca publicado. Alberti ha reunido sus impresiones de su estancia en Moscú en un artículo publicado en Luz de 22 de julio de 1933. Alberti y María Teresa de León traducen parte de ese libro y publican la traducción en Adelanto de la revista Octubre (1 de mayo de 1933).

En el número de Octubre de julio-agosto de 1933, R. Alberti publica su traducción de un poema de Aragón, hoy perdido y que sólo se conserva gracias a esa traducción: "Un organillo empieza a tocar en el patio." En Le crève-coeur aparece un poema emparentado con ése, titulado "Complainte pour l'orgue de la nouvelle barbarie"?.

Otro testimonio del contacto de Aragon con España es su Prólogo a "L'Espagne au coeur" que recoge poemas de Pablo Neruda. También se puede señalar como testimonio de su engarce con España el poema "La Santa espina" (II de "Deux poèmes d'outre-tombe"), en el que celebra el cantar popular español del mismo nombre ${ }^{8}$.

El conocimiento de la realidad española y el militantismo a favor de la República han podido ser elementos determinantes, o al menos coadyuvantes, en el interés que Aragon concede al arraigo popular de su poesía de ese momento.

Esas circunstancias, y la propia evolución del poeta respecto a su obra, van a provocar una actitud nueva en él. La realidad social de los años que preceden a las guerras le determinan a alejarse del surrealismo, tanto en lo que se refiere a la creación poética como a la práctica del verso; las circunstancias ofrecen ahora otros caminos y el poeta va a considerar que inaugura una época de "liberación de la voz". Vuelve la mirada a las formas de la canción y baladas antiguas, rescata el verso de medida fija y lleva su poesía al canto en exaltación de la tradición. Su conjunto Le crève-coeur (y en menor intensidad Les Yeux d'Elsa) plasma ese nuevo concepto de poesía que enraiza en el patrimonio cultural nacional. La rima va a ser uno de los elementos principales de su renovación. Unas palabras de Michel Murat resumen perfectamente el significado de este nuevo concepto de la rima en Aragon: "la

$\overline{7}$ En Euvres poétiques complètes, I, pp. 695-725. La Complainte en pp. 717-719.

8 Ibid., pp. 707-709, cuyo primer verso es : "Som i serem gent catalna". 
conjonction entre poésie, nation e histoire"'.

"J'ai pris et démoli la bastille des rimes"10, había proclamado con ufanía Victor Hugo. Pero el estudio de la rima utilizada en su obra revela que esa práctica iconoclasta ha sido quizás de alcance no tan destructor, y que el empleo que hace de ella encaja en los usos que se venían haciendo desde siglos antes, aunque con mayor amplitud. Las rimas que utiliza Victor Hugo entran con alguna frecuencia en la categoría que los críticos consideran como rimas "ricas" (con identidad de consonante de apoyo: jactance / potence; rumeurs / rameurs; toile / étoile. Se reconoce incluso que la rima constituía su preocupación mayor en el momento de crear el poema ${ }^{11}$. E incluso que en su obra la rima determina la forma y sentido del verso. Los críticos de su época, suelen considerar el valor creador de la rima, en oposición a quienes desde siglos vienen afirmando que la rima puede desviar y falsear el sentido que el poeta se proponía expresar ${ }^{12}$. La crítica admite actualmente como postulado aceptado que la rima condiciona todo el poema.

Aragón inicia una ruptura con los movimientos de su tiempo. El abandono de la rima por parte de los surrealistas ha provocado el abandono de la misma en los poetas contemporáneos que han negado su valor poético y la han condenado por considerarla elemento perturbador en la creación ${ }^{13}$. Muy

9 MURAT, Michel: “Aragon, la rime et la nation", The Romanic Review, January, 2001, pp. 185-199.

10 Les contemplations, Réponse à un acte d'accusation.

11 SÉCHÉ, Léon: Le Cénacle de Joseph Delorme. Paris: Mercure de France, 1912: «dans la facture du vers il laisse voir que son principal effort a toujours porté sur la richesse de la rime» (p. 112). Véase igualmente el ensayo de HOVASSE, Jean-Marc: «Victor Hugo créateur de la rime». CNRS, UMR 6563.

12 Era también la opinión de Juan Ramón JIMÉNEZ: "En el verso libre todo es de uno, nada viene traído de la palabra aconsonantada ni de la asonantada". (Carta a Ángela Figuera), Crítica paralela. Madrid: Narcea, 1975, p. 187. Tomo esta cita de DOMÍNGUEZ CAPARRÓS, José: "La rima entre el ritmo y la eufonía", en Estudios de métrica. Madrid: UNED, 1999, p 152.

13 La idea de que la rima es como una prisión para el poeta viene de lejos. En el siglo XVI, DU BELLAY evoca esta hipótesis en la Deffence, II, 7, que la recoge de SPERONI, Dialogue des langues, $\mathrm{f}^{\circ} 117 \mathrm{r}^{\circ}$. Datos procedentes de MÉNAGER, Daniel: «La rime en France de la Pléiade à Malherbe». Etudes littéraires, 1987, vol. 20, p 30 y nota 24. Se difundía de este modo la idea de verso francés libre, sin rima (Id. p 30). Y aunque esta tendencia no provocó un interés notable, 
al contrario, la rima significa ahora para él la recuperación de la libertad perdida por ser estimulante del trabajo de la invención.

Por otra parte, el poeta vive en su tiempo y es testigo de las mutaciones. Uno de los aspectos de la modernidad es la irrupción en la lengua de términos correspondientes a las nuevas técnicas de la física, de la mecánica, de la química, de las comunicaciones, etc. Y la utilización de ese vocabulario reciente, lejos de ser una traba a la libertad, enlaza con el mundo real, hace que el poema comunique con la realidad, establece relación entre el canto y las cosas y las cosas entran en la canción: "A cette heure où la déraisonnable rime redevient la seule raison. Reconciliée avec le sens. Et pleine de sens comme un fruit mûr de son vin". Nunca ha sido tan urgente como ahora hacer que las cosas canten.

Lo mismo que el verso medido, y como el engarce con las formas tradicionales, la rima es, pues, un elemento de afirmación y de contundencia en los momentos de derrota y desaliento. Pero ampliándola, ensanchando su dominio, abriéndole otras posibilidades de sonoridad y de significado, con lo cual Aragón se hace también innovador, indagador en la lengua. E1 concepto de la rima en este escrito de Aragon supera los límites de la rima tradicional, de tal modo que la rima (consonante) no se atiene ya sólo (o sólo siempre) al núcleo vocálico tónico y los elementos que siguen, sino que admite otros anteriores en diversas posiciones hasta alcanzar o incorporar sonidos en situación de encabalgamiento. Tan importante es este nuevo concepto de la rima que La rime en 1940 es considerado por Michel Murat como "una especie de manifiesto"14.

hubo ciertos ensayos como el soneto CXIV de l'Olive, la oda "Sur la naissance de François de Valois”, de RONSARD. El desdén de la rima implicaba el de lo vulgar y popular y la convicción de que la poesía libre alcanza la belleza más alta. También la crítica española clásica provoca la polémica en torno a la validez o necesidad de la rima: NEBRIJA, Juan del ENZINA, ARGOTE DE MOLINA y otros exponen razones diversas en torno a este problema. La pretensión a prescindir de la rima no tuvo eco en los tratadistas posteriores. A este respecto, véase DÍEZ ECHARRI, Emiliano: Teorías métricas del siglo de oro. Madrid: Revista de Filología española, anejo XLVII, pp. 118-125.

14 MURAT, Michel: “Aragon, la rime et la nation", cit. 
Con anterioridad a su experiencia, otros poetas han realizado otras posibilidades de rima, liberándola de las reglas rígidas del clasicismo. Rimbaud no respetó siempre las normas tradicionales. Apollinaire, dice Aragon, ha sido uno de ellos, quizás el más importante, renovando y modificando los conceptos de rima masculina y rima femenina: son rimas masculinas, según Apollinaire, las que terminan en vocal pronunciada o en vocal nasal, y femeninas las que terminan en consonante pronunciada, lleven o no una e muda final, y propone como ejemplo la estrofa de este poeta en la que aparece en fin de verso "malhabile" rimando con "exil":

Maraudeur étranger malheureux malhabile

Voleur voleur que ne demandes-tu ces fruits

Mais puisque tu as faim que tu es en exil

Il pleure il est barbare et bon pardonnez-lui.

(Apollinaire, Alcools, Le larron, Euvres poétiques, Pléiade, p. 91.)

Michel Murat prefiere denominar a estos dos tipos rima vocálica y rima consonántica ${ }^{15}$.

Los versos que siguen presentan los dos tipos de rima. Los versos 1,5 y 9 tienen rima femenina en -OR; los otros, masculina en $-\mathrm{U}$.

Même tout seul l'oiseau au fort

Du massacre ne s'est pas tu

Nous aurons chanté combattu

Ma belle amour mais où es-tu

Porteurs d'animaux et d'amphores

Voici venir doux et têtus

Les champs de Mai pleins de laitues

Comme à l'église les statues

Des saints pélerins zoophores

Peintes de toutes les vertus

(Aragon, "Le poème interrompu", Euvres, I, p. 713.)

Ejemplo de rimas masculinas en vocales nasales:

15 MURAT, Michel: «Il ne reste donc que deux types de rimes, que j'appellerai par commodité vocalique et consonantique», ibid., p. 188. 
Qu'était-ce qui faisait soudain

Un sanglot lourd dans le jardin

(Zone libre, I, Euvres, I, p. 720.)

En realidad esta práctica consiste en sustituir el respeto a la homografía por el de la homofonía, de modo que los sonidos finales de pronunciación semejante constituyen rima aunque la grafía sea distinta ${ }^{16}$. El propio Aragon lleva esa práctica al extremo:

Les femmes que nous intriguons

Cherchent à lire nos em-blèmes

Les sphinx ça connaît les dragons

Et d'idéales D-LM

Se battent contre leurs pro-blèmes

("Romance du temps qu'il fait",

Le crève-cour, Euvres, I, p. 712.)

y en el mismo poema aparecen estos versos:

Car me plaît de dire Moi je [...]

Je garde le secret du jeu

Il est aussi fou sinon pire

Qu'il était aux jours de Shakespeare

Otros ejemplos en su obra:

Comme un rire de loup dans la neige

Sept ans peut-être Et J'

Attends toujours que soit renversé le temps

(«Le papier quadrillé», Les Chambres, CEuvres, II,

p. 1093.)

Ils ne vont pas venir je vous le dis ils ne v'

Ont pas venir ce soir avec des lèvres neuves

(XII. "Le rendez-vous", Le Fou d'Elsa, Euvres, II

p. 839.)

Este ejemplo último presenta además la particularidad de

16 MURAT, Michel, considera que en fin de cuentas la rima francesa se resuelve en dos tipos: «Il ne reste donc que deux types de rimes, que j'appellerai par commodité vocalique et consonantique». Ibid. 
separar elementos no separables de un mismo vocablo, en este caso, una de las personas del verbo venir: "vont", que aparece escindida en $\mathbf{~}$ ' (radical, con apóstrofe añadido) al final de un verso y Ont (desinencia) al principio del siguiente. Nótese que la mayúscula de la desinencia refuerza la voluntad de separación, aun teniendo en cuenta el uso general de utilizar mayúsculas en palabra inicial de verso.

En los ejemplos que siguen no sólo no se respeta la homografía sino tampoco la homofonía: lèvres / lève en el primero y courges / coeur j' en el segundo:

Mon amour il ne reste plus

Que les mots notre rouge-à-lèvres

Que les mots gelés on s'englue

Le jour qui sans espoir se l-ève

Rêve traîne meurt et renaît

Aux douves du château de Gesvres

(“Les amants séparés”, Euvres, I, p. 705.)

Des hommes sous leurs toits fanés de courges

Se cachent mais au-dessus s'étend pour moi

Le royaume provisoire de ton coeur j'

Écoute j'écoute battre Tôt ou tard

(VIII, Les Chambres, Euvres, II, p. 1116.)

En estos otros, la consonante de la rima difiere $(\mathrm{d} / \mathrm{t})$, pero pertenecen a una misma categoría de consonantes dentales sonora la una, sorda la otra:

Tu n'as pas fait offrande à l'Etna de toi-même

Hölderlin

Heureux à son amour celui

Qui n'a survecu d'

Une minute

Le corps démâté démembré disjoint

(HöLDERLIN, Euvres, II, p. 1141.)

Je parle à l'autre au-dessus du Neckar pour la seconde

Moitié de ma vie

Et nul ne sait si l'on t'

Avait laissé pour les relire pour

Après jour 
les lettres de Diotima

(HölderLin, Euvres, II, p. 1141.)

Esta exploración de Aragon acerca de las posibilidades que pueden ofrecer las palabras en situación de rima, le lleva a veces, como se ve, a una experimentación que probablemente no será duradera. Es posible también que la lectura visual y la lectura oral tengan efectos distintos en el lector y que éste tenga una percepción diferente en un caso o en el otro.

\section{LA RIMA AMPLIADA}

La identidad de sonidos que exige la rima consonante a partir, y sólamente a partir, de la última vocal tónica ha sido durante siglos la norma generalmente aplicada. En el siglo XIX algunos poetas utilizan libremente la llamada consonante de apoyo que precede al núcleo vocálico tónico, sin que ello suponga una obligación normativa. Hubo sin embargo partidarios de que la rima tuviese una extensión más amplia hacia la izquierda utilizando no sólo la consonante de apoyo, sino otros elementos anteriores. La polémica debió de tener actualidad pues Alfred de Musset en una de sus Lettres de Dupuis et Cotonet t7 $^{17}$ tulada "Les Exagérés" protestaba contra quienes pretendían mermar la libertad del poeta con imposiciones de ese tipo.

Que los componentes de la rima pueden o deben comprender más elementos que los reconocidos según la norma, es idea antigua, lo cual parece desmentir la opinión de Andrés Bello que afirmaba que "la consonancia misma gusta menos cuando se extiende a más sonidos elementales que los indispensables"18. Se pensaba en Francia que el abandono de los ritmos latinos debía ser compensado con un mejoramiento o embellecimiento de la rima integrando en ella "les deux, les trois ou les quatre syllabes d'une seule diction assises en la ${ }_{17}$ La Revue Des Deux Mondes de 15 de mayo de 1837.

18 Citado por DEVOTO, Daniel: Para un vocabulario de la rima española. Paris: Cahiersde Lingistique hispanique médiévale, vol. 10, Université de Paris XIII, 1995, entrada "rica", p. 152. 
fin d'un vers" como afirmaba Thomas Sebillet ${ }^{19}$. Es evidente que esta incitación no se podía cumplir siempre. Sí, en cambio, la extensión de la rima a uno o más elementos anteriores. Las palabras esdrújulas permiten en español el alargamiento de la rima, lo cual también ha dado motivo de polémica entre los tratadistas de los siglos pasados ${ }^{20}$.

Aragon no dedica a este aspecto de ampliación la rima una reflexión innovadora, limitándose a recordar que frente al desdén de la rima en la poesía reciente, el poeta Robert Desnos consiguió escribir dos versos que son rima en toda su integridad, extendiéndola a la totalidad de los componentes de cada verso. Son los tan conocidos:

Gal, amant de la Reine, alla (tour magnanime),

Galamment de l'arène à la Tour Magne à Nîmes,

que es también el caso de estos otros versos, más recientes, de Ángel González:

dore mi sol así las olas y la [...]

do re mi sol la si la sol la si la.

(Ángel GonzÁlez, "Calambur”, Palabra sobre palabra. Barcelona: Seix Barral, 1992, p. 298.)

Son versos, en ambos casos, en los que todo es rima y que se pudieran designar como versos de "rima integral".

Este vaivén entre desdén de la rima y su extensión a la totalidad del verso, justifica la indagación en la poesía sobre las posibilidades de integración en la rima de elementos fónicos que la preceden.

La ampliación más sencilla consiste en integrar la consonante de apoyo, que se ha empleado en realidad desde mucho antes, con o sin intención de hacerlo. He aquí algunos ejemplos de épocas sucesivas, fácilmente detectados:

19 SEBILLET, Thomas: Art poétique françoys (1548). Édition critique, avec une introduction et des notes, thèse complémentaire pour le doctorat ès lettres, présentée à la Faculté des lettres de l'Université de Paris, par GAIFFE, Félix, 1910.

20 Sobre la rima esdrújula puede verse PARDO, Arcadio: "El caso del endecasílabo esdrújulo". Rhythmica, 2005-2006, V-VI, N 5-6, pp. 175-211. 
1) Extensión a la consonante de apoyo:

C'est d'umaine beaulté l'yssue!

Les bras cours et les mains contraites,

Les espaulles toutes bossues;

Mamelles, quoy! toutes retraites;

Telles les hanches que les tetes.

(François Villon, Testament, vv. 517-511.)

Par Castor et Pollus, vos deux frères jumeaux,

Par la vigne enlacée à l'entour des ormeaux,

Par le nouveau Printemps, fils aîné de Nature,

Que seule vous serez ma dernière aventure

(Ronsard, Premier livre des sonnets pour Hélène, I. Euvres poétiques, Pléiade I, vv 2-3, 5 y 8.)

Soutenir vos rigueurs par d'autres cruautés,

Et laver dans le sang vos bras ensanglantés.

(RACINE, Britannicus, acte IV, scène III.)

Cuatro casos en una misma estrofa:

Pendant les guerres de l'empire, Goethe, au bruit du canon brutal, Fit le Divan occidental,

Fraîche oasis où l'art respire.

(Тн. Gautier, Émaux et camées, Préface. Garnier, 1954, p. 3.)

Douleur qui doubles les destins

La licorne et le capricorne

Mon âme et mon corps incertain

Te fuient ô bûcher qu'ornent

(Apollinaire, "Poèmes à Lou", VIII,

Euvres poétiques, p. 385.)

y en la obra del propio Aragon:

Refond les gestes d'autrefois dans leur cachot

Et semble-t-il ça leur fait ni froid ni chaud

(ARAGON, "Vingt ans après", Euvres, I, p. 697.)

Pueden multiplicarse los ejemplos ad infinitum. 
2) Extensión al grupo consonántico anterior:

Il règne sur la ville une nuit négatrice

L'Arlequin blanc et noir noir et blanc devenu

N'y voit rien de changé sinon que les actrices

(ARAGON, "La nuit en plein midi”, Euvres, I, p. 765.)

3) Extensión a la sílaba anterior en otro poema del mismo:

Que les heures tuées

Guerre à Crouy-sur-Orcq

Meurent mal Et tu es

Mon âme et mon vautour

Camion de buées

(“J'attends sa lettre au crépuscule", Euvres I, p. 699.)

El último de estos versos presenta una modificación en la consonante.

4) Extensión a la consonante de apoyo precedida de vocal perteneciente a la sílaba anterior:

Partez: mon ennemi ne vous peut échapper,

Ou plutôt il ne faut que les laisser frapper

(Racine, Andromaque, Acte IV, scène III.)

Le temps a retrouvé son charroi monotone

Et rattelé ses bœufs lents et roux c'est l'automne

(ARAGON, "Vingt ans après", Le crève-cour, EEuvres I, p. 697.)

5) Incorporación de la consonante de apoyo y parte de la sílaba anterior:

Dois-je croire qu'au rang où Titus la destine

Elle m'écoute mieux que dans la Palestine

(Racine, Bérénice, Acte I, scène II.)

6) Incorporación de la sílaba anterior a la consonante de apoyo:

Aux puantes prisons où les saints zélateurs 
Quand nous les consolons nous sont consolateurs.

(Agrippa D’Aubigné, "La Chambre dorée",

Euvres, Pléiade, pp. 107-110.)

Je puis faire les rois, je puis les déposer;

Cependant de mon cour je ne puis disposer

(RAcine, Bérénice, Acte III, scène I.)

Elle ravale ainsi l'écume de sa haine,

Et, ne comprenant pas les desseins éternels,

Elle-même prépare au fond de la Géhenne

Les bûchers consacrés aux crimes maternels.

(BAudelaire, "Bénédiction", Les fleurs du mal.)

Amour abandonons aux ténnèbres mentales

Leur carnaval imaginaire Il me suffit

Du monde tel qu'il est sur les cartes postales

La gesticulation d'ombres monumentales

(ARAGON, "La nuit en plein midi”, EEuvres I, pp. 766-767.)

7) Incorporación de más de una sílaba:

C'est là que nous avons notre gouvernement, Et notre temps perdu dans le lanternement

(CH.PÉGUY, "Présentation delaBeauceàNotreDamedeChartres", Euvres poétiques complètes, Pléiade, p. 899.)

Es evidente que la incorporación de todos esos elementos sonoros que aquí se anotan como variaciones métricas, tienen o pueden tener un valor de significantes que el poeta ha utilizado por puro instinto y que la crítica debe poner de relieve. Las palabras siguientes de Angelo Marchese y Joaquín Forradellas parecen perfectamente adecuadas, a pesar de las reservas que han expresado en las líneas que preceden: "es indudable que en muchos casos el significante, como vehículo de la rima pero también en función autónoma, alcanza y revela elementos inconscientes"21. Especialísimo interés merece a este respecto, como es sabido, el libro Poesía española, de Dámaso Alonso, cuyas referencias es inútil precisar aquí, por ser obra muy conocida.

${ }^{21}$ Diccionario de retórica, crítica y terminología literaria. Barcelona: Ariel, 1986, p. 351. 
Distingue Aragon otros aspectos renovadores de la rima que él denomina "Compleja", "En síntesis" y "Encabalgada". Pero antes de exponer estas otras modalidades, conviene explorar en poesía española si ha habido o hay casos semejantes a los que se han expuesto en poesía francesa.

J. Domínguez Caparrós, ha señalado que en el libro Acordes disonantes y otros poemas seguidos de la tercera edición de la Teoría general de la Rima (1951) de Daniel Castañeda, se encuentra toda una gama de variantes de rima registrando quince posibilidades, de las cuales sólamente los tipos 1 (praderas / maderas), y el 2 (fuga / oruga) corresponden con el uso preceptivo de la rima consonante ${ }^{22}$. Los trece tipos restantes presentan modalidades que, por sus combinaciones nada familiares, tampoco han tenido seguidores. Varios tipos de rimas "extrasistemáticas" pueden verse en el Diccionario de retórica, crítica y terminología literaria de Angelo Marchese y Joaquín Forradellas, ya citado, en el apartado RIMA, 1. Clases de rima ${ }^{23}$.

También se encuentran fácilmente ejemplos en poesía española de rima con consonante de apoyo. Para mayor claridad me limito a los casos en que la consonante de apoyo es idéntica, apartando aquellos otros en que aparecen en las rimas consonantes de apoyo fonéticamente emparentadas, como son por ejemplo las dentales: candado / costado, en un soneto de Carlos Murciano ${ }^{24}$. Los ejemplos que siguen representan épocas diversas:

22 DOMÍNGUEZ CAPARRÓS, José: "Sobre rimas extrasistemáticas", en Estudios de métrica, cit., pp. 171-179.

23 MARCHESE, Angelo, y FORRADELLAS, Joaquín: Diccionario de retórica, crítica y terminologia literaria, cit., p. 352.

24 Dice la voz: «Abre la puerta»; Digo

"Soy yo la puerta y cierro con candado".

"¡Llaves, aquí! -dice la voz-, al lado

de este muro sin hueco no postigo".

Rueda en lluvia la noche. Digo: "Amigo,

ni hueco ni postigo mi costado

tiene, pero la puerta la he cerrado

a piedra y lodo y no abriré". Te sigo

(Soneto "La puerta", en Como un agua escondida. Córdoba: Caja Sur, 2008, p. 14.) 
Cruz cruzada panadera tomé por entendedera

(Libro de buen amor, est. 116)

probó tener la muela como avía usado [...]

dis: ' Ay molino resio! Aun te vea casado

(Libro de buen amor, est. 195.)

Y pues os he ganado por la mano [...]

que cuando vos habléis como hombre humano

(Francisco de Aldana, "Canción a Cristo crucificado", vv. 67 y 70 .)

con que mi pena atrevida

hoy me tiene suspendido

entre su muerte y su vida

(CALDERón, "No hay cosa como callar", Jornada I.)

Largas horas de espera...Eternidades

que llenan de ansiedad mis soledades...

(Francisco VillaesPesa, "La canción del recuerdo", I, El libro del amor y de la muerte.)

Regente de esta hermosura.

Pinta bien: se me apresura

(J. Guillén, "Amiga pintura”, Cántico.)

Lúbrica polinesia de lunares

es la pulida mar de tu cadera.

Trópico del tabaco y la madera

mecido por las olas de tus mares.

(ÁNgel GonzÁlez, Geografía humana.

"Calambur", Palabra sobre palabra.)

La incorporación de elementos anteriores a la consonante de apoyo es poco frecuente en poesía española y siempre involuntaria e inconsciente. Los ejemplos que se recogen a continuación demuestran que en este caso la poesía española ha empleado las mismas posibilidades que se han visto en poesía francesa, y que ese empleo se puede fácilmente codificar como se ha hecho más arriba. Se escogen los ejemplos que siguen por presentar incorporación de elementos múltiples. 
1) Consonante de apoyo precedida de vocal:

ya causa elemental de las primeras, tuyo es mi canto; si escuadrón volante, que en arrullos y quejas lastimeras

(Gabriel De Henao, Rimas, "Al palomar del Conde de Monterrey”, Valladolid: Fundación Jorge Guillén, 1997,

De la montaña sueña celestiales rutinas [...]

De grillo de las cándidas églogas matutinas

(Julio Herrera y Reissig, "El Despertar",

Los éxtasis de la montaña. Poesía completa y prosas.

Buenos Aires, Col. Archivos, 1998, p. 17.)

mas tenían sus ojos tal expresión amante [...]

Los surtidores vierten lágrimas de diamante...

(Francisco Villaespesa, "Veladas sentimentales", II, El libro del amor y de la muerte.)

Ya escucho, a solas, el derrumbamiento [...]

el claustro ensimismal del pensamiento

(Blas de Otero, "Postrer ruido", Ancia, p. 50.)

2) Consonante de apoyo precedida de elementos de la sílaba anterior:

¿Qué es el placer, la vida y la fortuna [...]

Una carrera larga e importuna

(José ZorRILla, "Gloria y orgullo".)

3) Consonante de apoyo precedida de la sílaba anterior:

Éste, pues, sólo pudo alto ardimiento

ceder a nuestro propio entendimiento

(Sor J. InÉS DE la CRuz, "Neptuno alegórico", vv. 255-256.)

El más profundo problema, -el de la inmortalidad [...]

Que si el cangrejo se muere -todo en su totalidad

(Miguel de Unamuno, Cancionero.

Madrid: Akal, 1984, p. 70.) 
Fatiga del domingo... Extraordinario [...]

de este modesto ensueño consuetudinario!

(Manuel Machado, Caprichos. Madrid, 1905.)

que Dios, el solo vivo, no existiera,

o que, existiendo, sólo consistiera

(Blas de Otero, "Soneto Basta", Ancia, p. 40.)

o de parte de la sílaba anterior:

Tras la cortina de mi alcoba espera [...]

Alguien que me conoce desespera

(C. Murciano, Madrid, Sonetos de la otra casa. Endymion, p. 15.)

La integración de elementos precedentes a los de la rima propiamente dicha puede producirse fácilmente cuando la rima utiliza palabras derivadas. He aquí algunos casos:

En cielo impírio, trono más conforme

$[\ldots]$ adonde la uniforme y omniforme [...]

porque el ángel en él su paso informe

(Francisco de Aldana, "Parto de la Virgen", vv. 401-408,

No viste siempre en firme lazo atadas[...]

son con frecuencia exemplo desatadas.

(Francisco de Rioja, Soneto XXXVIII, Poesía.

Madrid: Cátedra, p. 197.)

que aunque no pueda yo dalle consuelo

compañía será mi desconsuelo

(Francisco de Aldana, "Canción a Cristo

Crucificado", vv . 90 y 93, p. 288.)

lo que la quiero, ingrata, corresponde;

si digo que es mi vida, me responde

(Lope De Vega, "Desdenes de Juana

y quejas del poeta", Rimas humanas y divinas.)

Por puntos sobre la puerta un resplandor trasciende;

$\mathrm{Y}$ el misterioso suspiro que hacia la noche asciende

(Julio Herrera y Reissig, "Le sommeil de Canope".

Traducción del poema de Albert Samain

Le sommeil de Canope, Poesía completa y prosas, p. 402. 


\section{RiMA COMPLEJA}

Consiste este tipo de rima en descomponer en varias palabras los sonidos de una rima anterior. Aragon explica: «Je veux parler de la rime complexe, faite de plusieurs mots décomposant entre eux le son rimé». No parece tan evidente como suele decirse que esta rima «compleja» corresponda a la rima «équivoque» de los retóricos del siglos XV, pues la rima "équivoque" se refiere a la repetición de palabras de la misma pronunciación pero con sentidos distintos (point $=$ punto y point $=$ negación; je suis $=$ verbo être y je suis $=$ verbo suivre). Más adecuado sería decir que esta rima compleja puede mostrar algún parentesco con la rima "équivoque", si se considera la identidad de sonidos que en la grafía aparecen separados y que constituyen rima con palabra rima anterior. Es el caso de los ejemplos que sigue: "ivresse-vivre est-ce", etc. Las palabras rima rebasan los límites de la rima normativa:

Préfèrent à leur vie un seul moment d'ivresse

Un moment de folie un moment de bonheur

Que savent-ils du monde et peut-être vivre est-ce

Tout simplement Maman mourir de très bonne heure

("La valse des vingt ans", Le crève-cœur, CEuvres I, p. 706.)

Que les heures tuées

Guerre à Crouy-sur-Orcq

Meurent mal Et tu es

Mon âme et mon vautour

("J'attends sa lettre au crépuscule", Le crève-cœur,

Euvres I, p. 699.)

Aunque este caso no presenta en su obra una frecuencia extremada, pueden encontrarse en ella algunos otros ejemplos:

Sillonné de vents et d'années

Taché talé de tant de siècles

Ô déchirures du drapeau

Avec toutes les tares de l'humanité sur la terre avec l'

Histoire écrite aux rides de ma peau,

(XXIV, Le Fou d'Elsa, Cuvres, II, p. 877.) 
rimando siècle / avec l' con separación del artículo y del sustantivo que pasa a cabeza del verso siguiente $\mathrm{y}$, en el ejemplo que sigue, separando el pronombre sujeto del verbo que pasa igualmente a ser cabeza del verso siguiente:

Parler d'amour c'est parler d'elle et parler d'elle

C'est toute la musique et ce sont les jardins

Interdits où Renaud s'est épris d'Armide et l'

Aime

(“Petite suite sans fil”, Le crève-cœur, II, Euvres, I, p. 702.)

J'écoutais les longs cris des chalants sur l'Escaut

Et la nuit s'éveillait comme une fille chaude

La radio chantait Elle ne blesse qu'au

Cœur ceux qu'atteint cet air banal où l'amour rôde

("Le printeps", id, I, p. 709.)

Les champs bruns pleins de coqs chanteurs et de fétus

De paille ont pris ce matin l'air de chiens battus

Capitaine de jour soleil blanc que fais-tu

Comme un qui traîne dans sa chambre

("Petite suite sans fil", III, Euvres I, p. 703.)

Es de notar que casos de separación de determinante y sustantivo se encuentran en poesía española sin dificultad o bien de otros elementos que en la frase son átonos y que por su situación en posición de rima cobran intensidad tónica ${ }^{25}$ :

Esta modalidad de rima compleja ha sido bastante utilizada por los poetas del XIX. En cambio se encuentran muy pocos ejemplos en poesía española y, si los hay, los tratadistas no suelen considerarla como modalidad que difiera de la rima consonante normativa.

Cabe citar a este respecto unos versos de Carlos Murciano

25 He aquí dos ejemplos:

Y que cuando los he hecho

Ha sido en el corto espacio

Que ferian al ocio las

Precisiones de mi estado.

(Sor JuAna InÉs de La Cruz, Obra selecta. Barcelona: Planeta, p. 4.

con aquella brisa de

su palabra y con la fe

que en su palabra ponía.

(José María Pemán, Elegía de Jacinto Ilusión.) 
en los que aparece un caso que se puede admitir como de rima compleja, por encontrarse en el verso 7 de un soneto, con tres anteriores que riman en -ola:

y busco en él una palabra sola.

Y no la encuentro -niña, niña- no la encuentro

(CARlos Murciano, Sonetos de la otra casa.

Madrid: Endymion, p. 18);

o este otro ejemplo semejante: el verso 7 de un soneto presenta como rima dos palabras separadas:

donde se miran sin quitarse velos

gesticulando a semejanza de los

peleles

(CARlos E. DE ORY, "Sobre los vivos y los muertos", Soneto vivo. Barcelona: Anthropos, p. 71.)

y también estos otros, versos 10 y 12 de otro soneto del mismo poeta:

confundiré la noche con tu pelo $[\ldots]$

será mi sombra por tu alcoba y te lo

juro

(CARlos E. DE Ory, "Cuando haya muerto todo",

Soneto vivo, p. 121.)

Y en obra más reciente :

espumosa y floral, desnuda y sola

niegas tu cuerpo al mar, ola tras ola,

(Ángel GonzÁlez, "Calambur", Palabra sobre palabra, p.

con rimas semejantes a las de Carlos Murciano citadas, aunque en este caso se trata más bien de la consonante de apoyo que de la rima en sí.

Conviene señalar igualmente el caso especial y poco frecuente en que todas las palabras de un verso tienen eco en las del verso siguiente, como en este ejemplo de "rima integral" 
citado más arriba:

dore mi sol así las olas y la [...]

do re mi sol la si la sol la si la.

(ÁNGel GonzÁlez, “Calambur”, p. 298.)

Puede ser que con mayor atención y tiempo que dedicar a la búsqueda, puedan encontrarse en poesía española otros casos de rima compleja de los que ahora no dispongo.

\section{RiMA EN SÍNTESIS}

Se produce rima en síntesis, según Aragón, cuando una palabra reúne sonidos separados en verso anterior. Se trata de una modalidad que invierte el orden de la rima compleja. También en esta modalidad puede ocurrir que las palabras sobrepasen la extensión de la rima propiamente dicha, como en todos los ejemplos que siguen:

L'Ode Açoka cadre avec la

Strophe en fenêtre de lorette;

Et de lords papillons d'éclat

Fiantent sur la Pâquerette.

(Rimbaud, "Ce qu'on dit au poète à propos des fleurs", en Euvres. Paris: Mercure de France, 1947, p. 74.)

Nous ne comprenons rien à ce que nos fils aiment Aux fleurs que la jeunesse ainsi qu'un défi sème Les roses de jadis vont à nos emphysèmes

(ARAGON, "Chant de la zone des étapes", Le crève-cour, (Euvres I, p. 704);

ejemplo en el que la palabra emphysème reúne la diversidad anterior.

También de Aragon son los siguientes:

Vingt ans L'espace à peine d'une enfance et n'est-ce

Par sa pénitence atroce pour notre aînesse

("Vingt ans après", Le crève-cœur, Euvres I, p. 697.)

La France sous nos pieds comme une étoffe usée 
S'est petit à petit à nos pas refusée

("La nuit de Dunkerque", Les yeux d'Elsa, Euvres I, p. 762.)

Je crierai je crierai Mes yeux que j'aime où êtes

Vous Où es-tu mon alouette ma mouette

("La nuit de Dunkerque", Euvres, I, p. 763.)

On jurerait dit-il que c'est Paris si on

Ne refusait de croire aux apparitions

("La nuit d'exil", Euvres I, p. 764.)

Amour n'auras-tu pas pitié de mon grand âge

Amour assez longtemps ne m'as-tu point haï

Amour dans le cercueil aime-ton d'avantage

("Plainte pour la mort de Madame Vittoria Colonna

Maruise de Pescara", Euvres I, p. 777.)

Un bal où

Ni toi ni moi n'étais va s'ouvrir. Il commence

Les violons rendraient les poète jaloux

("Petite suite sans fil", Le crève-cour,

II, Euvres, I, p. 702.)

Son raros los ejemplos en poesía española. Los versos que se citan de C. E. de Ory tienen identidad de consonante de apoyo:

tanto en mis pies como en mis manos $\mathbf{y}$

despeño la cabeza como si

en tus plumas

("Bajos fondos", Soneto vivo, p. 72);

y este ejemplo final de esta modalidad:

me arrojo en tu silencio, a tientas ando... Me apartas, pegas con tu brazo fuerte contra mi fe. No finjas defenderte: ¿no ves que tanta fiebre está enfermándome?

(Blas de Otero, "Cara a cara", Ancia, p. 46.)

\section{Rima ENCABALgADA}

La denominación de «rima encabalgada» no tiene sentido 
entre nosotros. Por ser la rima límite del verso y anuncio de pausa versal, la rima no puede de ninguna manera desplazar parte de sus componentes al principio del verso siguiente. Y efectivamente, no existen casos de esta modalidad en poesía española. La separación de una palabra en dos fragmentos (la tmesis) no entra en esta modalidad. Ni tampoco los casosen que un verso recoge sonidos vocálicos o consonánticos de la rima del verso anterior.

Aragon inventa este tipo de rima (al que algunos llaman "rima de Aragon" ${ }^{26}$ ) que, según él, inaugura lo que llama "encabalgamiento moderno" que no consiste en desplazar al principio del verso siguiente una parte de un sintagma o componentes de la frase, como lo hacen los encabalgamientos suaves o abruptos, sino encabalgar sonidos prolongando de esta manera los efectos propios de la sonoridad de la rima, y por lo tanto, enriqueciendo, con esa fonación dilatada, su significado. Pudiendo la parte encabalgada de la rima reducirse, como lo muestran algunos ejemplos que se citan aquí, a una sola consonante o grupo consonántico (Trop, Doute, La). La rima no será, pues, marca de fin de verso, sino etapa transitoria en la sonoridad general del poema. En palabras suyas: "Je préconiserai ici l'enjambement moderne [...] où ce n'est pas le sens seul qui enjambe, mais le son, la rime qui se décompose à cheval sur la fin du vers et le début du suivant":

Ne parlez plus d'amour. J'écoute mon cœur battre Il couvre les refrains sans fil qui l'ont grisé Ne parlez plus d'amour. Que fait-elle là-bas Trop proche et trop lointaine ô temps martyrisé.

(I, "Petite suite sans fil”, II, Euvres, I, p. 702.)

Ah parlez-moi d'amour ondes petites ondes Le cœur dans l'ombre encore a ses chants et ses cris Ah parlez-moi d'amour voici le jour où l'on D-oute où l'on redoute où l'on est seul on s'écrit Ah parlez-moi d'amour Les lettres que c'est long De ce bled à venir et retour de Paris

\footnotetext{
26 «Dirais-je que pour avoir démonté aux yeux de tous la rime enjambée à qui certains ont depuis donné mon nom, je ne me sens ni deshonoré, ni détroussé par moi-même.» (Arma virumque cano, Euvres, I, pp. 745-746.)
} 
(I, 702 y "Petite suite sans fil”, II, Euvres, I, p. 702.)

Les malédictions des échelles franchies

Devrait-elle toujours peser sur nos épaules

Nos vignes nos enfants nos rêves nos troupeaux

La colère du ciel peut-elle être fléchie

(“Ombres", Euvres, I, p. 721.)

Ou le charme d'un soir dans les port de Toulon

Bref comme st le bonheur qui survit mal a l'ombre

("Elsa je t'aime", Euvres, I, 724.)

Ce quatrain qui t'a plu pour sa musique triste

Quand je ne l'ai donné comme un trèfle flétri

Stérilement dormait au fond de ma mémoire

("Elsa je t'aime", ib., p. 725.)

Esta modalidad nueva supone para Aragon una ampliación de la sonoridad de un verso hacia el siguiente, lo cual precipita el movimiento entre los versos y que Aragon justifica como necesidad "que le sens supérieur du poème vient dicter". Conviene señalar que la parte encabalgada no queda suelta, aislada como si fuera un fragmento de palabra desplazado, sino que esa parte inaugura, al mismo tiempo, otra palabra distinta; de modo que la parte encabalgada participa a la vez del sentido de la rima y del nuevo de la palabra situada en cabeza de verso, y no modifica el orden sintáctico de la frase.

De las tres modalidades (compleja, en síntesis y encabalgada) sólo la encabalgada constituye une verdadera innovación en poesía francesa, sin antecedentes en épocas anteriores.

Las experiencias, que también son propuestas, de Aragon en sus modalidades de rima "compleja", rima "en síntesis" y rima "encabalgada", no han tenido, salvo error por parte mía, otras manifestaciones en su obra posterior. Todo sucede como si la "urgencia" que la guerra ha exigido en él de proclamar el uso de la rima como un acto de resistencia y de arraigo, desaparece una vez el conflicto bélico terminado. Aragon abandona esas experiencias que son de difícil continuación, para venir de nuevo a los usos precedentes, si bien es verdad que la rima ha sacudido las trabas que imponían las normas clásicas y que 
su obra emplea la rima con gran libertad.

$\mathrm{Ni}$ en su obra posterior ni en los otros poetas se encuentra el ejercicio de los tipos de rima propuestos, de tal modo que se pueden considerar como un islote en la historia de la rima. Pues además de la exigencia del momento histórico, que ya ha perdido actualidad, el empleo de esos tipos de rima exige un virtuosismo nada frecuente y un sentido y maestría del lenguaje que Aragon posee como pocos poetas.

Es posible que otras experiencias aparezcan en la poesía futura, pues como dice Daniel Menagre con palabras suyas citadas en el encabezamiento de este trabajo, «On n'en a jamais fini avec la rime. On la croit morte [...] et voilà derechef qui occupe les poéticiens, intrigue les poètes, reparaît là où on ne l'attendait plus».

Buceando en la poesía española he podido dar con algunos ejemplos que pueden considerarse como de rima compleja y de rima en síntesis. Ninguno, en cambio, de rima encabalgada que parece no se aviene con la índole misma del lenguaje; teniendo en cuenta también que el ejemplo de Aragon no ha tenido difusión en España, y por lo tanto no ha incitado a nadie a ensayar nuevos aspectos de rima.

Quienes leen atentamente poesía española pueden detectar casos de rima de uso esporádico. Las propuestas de Daniel Castañeda no han tenido fortuna, como tampoco las de Luis Ángel Casal de "rima potencial o en potencia". Algunos investigadores han podido captar casos aislados de rimas no frecuentes, como la "rima en caída" señalada por Antonio Carvajal. ${ }^{27}$ Pero estas tentativas, voluntarias en los unos, intuitivas en otros, aparecen ahora como experiencias aisladas que en nada modifican el concepto de rima tradicional.

Más fortuna ha tenido y tiene la rima ampliada hacia la izquierda que los poetas utilizan ya con frecuencia espontáneamente, y que supone un ensanchamiento de gran riqueza.

27 El estudio de DOMÍNGUEZ CAPARRÓS, José, ya citado, «Sobre rimas extrasistemáticas», expone con claridad todos estos casos. 